\title{
Gadofosveset trisodium in coronary magnetic resonance angiography at 3 Tesla
}

\author{
Fabio S Raman ${ }^{*}$, Mark A Ahlman', Jianing Pang ${ }^{3,5}$, Filip Zemrak ${ }^{4}$ Debiao Li ${ }^{3}$, David Bluemke ${ }^{1,2}$ \\ From 17th Annual SCMR Scientific Sessions \\ New Orleans, LA, USA. 16-19 January 2014
}

\section{Background}

Coronary magnetic resonance angiography (MRA) at 3T suffers from imaging inconsistencies compared to $1.5 \mathrm{~T}$ despite the use of gadolinium-based contrast agents (GBCAs). Gadofosveset Trisodium (Ablavar ${ }^{\circledR}$, Lantheus Medical Imaging), with its high relaxivity and long intravascular residence time, offers greater potential over standard GBCAs to improve evaluation of the coronary arteries. Compared to its validation in larger arteries, the optimum dosage for coronary MRA has yet to be assessed. The purpose of the study was to evaluate the diagnostic potential of a $0.06 \mathrm{mmol} / \mathrm{kg}$ dose of Gadofosveset compared to a standard clinical dose of $0.03 \mathrm{mmol} / \mathrm{kg}$, using a free-breathing whole-heart coronary MRA protocol with $1.0 \mathrm{~mm} 3$ spatial resolution and $100 \%$ navigator efficiency. The injection protocol was optimized for the prolonged pharmacokinetics of Gadofosveset.

\section{Methods}

Twenty two contrast enhanced CMR scans were performed in 11 subjects [ 2 (18.2\%) male; $27.3 \pm 6$ years; BMI $=23.1 \pm 3 \mathrm{~kg} / \mathrm{m} 2]$ on a $3.0 \mathrm{~T}$ Verio Siemens scanner, using

\begin{tabular}{|c|c|c|c|c|c|c|}
\hline \multirow[b]{2}{*}{ Level } & \multicolumn{2}{|c|}{ SNR } & \multirow[b]{2}{*}{$P$ value } & \multicolumn{2}{|c|}{ CNR $_{\text {myo }}$} & \multirow[b]{2}{*}{$P$ value } \\
\hline & $\begin{array}{l}\text { Single } \\
\text { Dose }\end{array}$ & $\begin{array}{c}\text { Double } \\
\text { Dose }\end{array}$ & & $\begin{array}{l}\text { Single } \\
\text { Dose }\end{array}$ & $\begin{array}{c}\text { Double } \\
\text { Dose }\end{array}$ & \\
\hline \multicolumn{7}{|l|}{ Large Vessels } \\
\hline Left Ventricle & $12.98 \pm 4.09$ & $20.74 \pm 7.14$ & 0.003 & $7.03 \pm 2.37$ & $10.55 \pm 4.88$ & 0.03 \\
\hline Right Ventricle & $15.41 \pm 8.72$ & $25.37 \pm 9.48$ & $<0.001$ & $9.45 \pm 7.13$ & $15.17 \pm 7.62$ & 0.004 \\
\hline Desc. Aorta & $11.71 \pm 4.04$ & $19.35 \pm 9.01$ & 0.004 & $5.75 \pm 3.47$ & $9.16 \pm 6.64$ & 0.08 \\
\hline Prox. Aorta & $15.63 \pm 5.36$ & $27.59 \pm 9.65$ & $<0.001$ & $9.67 \pm 3.73$ & $17.40 \pm 7.76$ & 0.004 \\
\hline Overall & $13.93 \pm 5.90$ & $23.26 \pm 9.21$ & $<0.001$ & $7.80 \pm 4.68$ & $13.07 \pm 7.40$ & $<0.001$ \\
\hline \multicolumn{7}{|l|}{ Coronaries } \\
\hline LMS & $12.37 \pm 3.91$ & $23.03 \pm 7.45$ & $<0.001$ & $6.42 \pm 2.73$ & $12.83 \pm 6.51$ & 0.003 \\
\hline LAD & $15.20 \pm 3.88$ & $26.12 \pm 9.86$ & 0.001 & $9.25 \pm 2.68$ & $15.93 \pm 9.71$ & 0.03 \\
\hline LCX & $11.21 \pm 3.08$ & $17.24 \pm 5.25$ & 0.05 & $6.05 \pm 2.28$ & $8.11 \pm 5.14$ & 0.24 \\
\hline RCA & $18.13 \pm 6.29$ & $29.54 \pm 11.64$ & 0.01 & $12.26 \pm 4.80$ & $19.57 \pm 11.92$ & 0.07 \\
\hline Overall & $14.40 \pm 5.02$ & $24.18 \pm 9.67$ & $<0.001$ & $8.52 \pm 4.01$ & $14.27 \pm 9.40$ & $<0.001$ \\
\hline \multicolumn{7}{|l|}{ Other } \\
\hline Myocardium & $5.95 \pm 2.30$ & $10.20 \pm 3.12$ & $<0.001$ & & & \\
\hline
\end{tabular}

'Department of Radiology and Imaging Sciences, National Institutes of

Health, Bethesda, Maryland, USA

Full list of author information is available at the end of the article

(c) 2014 Raman et al.; licensee BioMed Central Ltd. This is an Open Access article distributed under the terms of the Creative Commons 


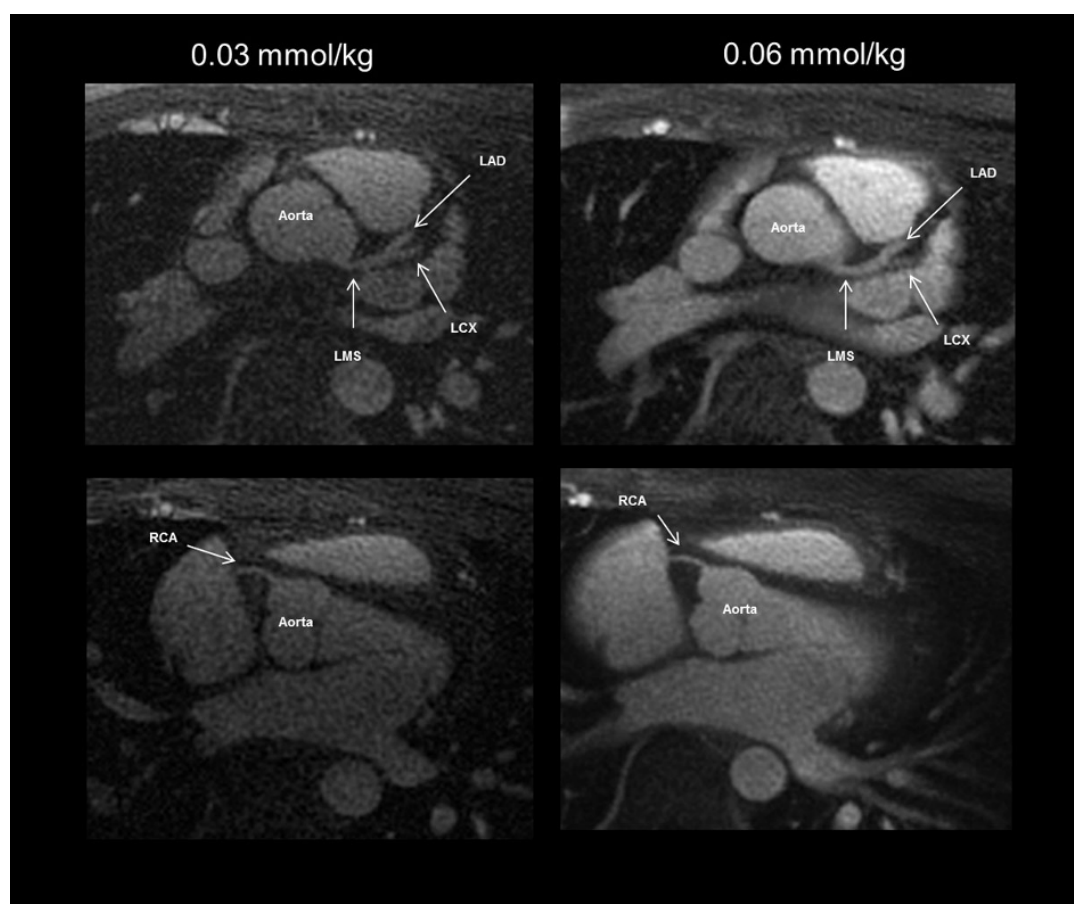

Figure 2 Axial slices through the heart from a healthy study subject at a single- and double-dose of Gadofosveset. Arrows indicate the locations of the ROI placement for measurement of the proximal sections of the coronary arteries. The aorta, left main stem (LMS), left anterior decending (LAD), left circumflex $L C X$,and right coronary artery $(R C A)$ are shown.

an inversion-prepared spoiled gradient-echo sequence (modified from Ref. [1]). The two scans were separated by a 30-60 day interval, using dosages of either $0.06 \mathrm{mmol} / \mathrm{kg}$ or $0.03 \mathrm{mmol} / \mathrm{kg}$ of Gadofosveset. Quantitatively, signalto-noise ratio (SNR) and contrast-to-noise ratios (CNR) were measured. Qualitative AHA quality scores were evaluated [2]. Pairwise, Student's t-test and Wilcoxon rank test were performed for quantitative and qualitative assessment (MedCalc Software v12.2.1, MariaKerke, Belgium).

\section{Results}

Overall, SNR and CNR was higher $(\mathrm{p}<0.001)$ in the coronary arteries for double- over single-dose of Gadofosveset $(24.18 \pm 9.67$ vs. $14.40 \pm 5.0$ and $14.27 \pm 9.40$ vs. $8.52 \pm$ 4.01, respectively, Figure 1). Individual coronary arteries demonstrated greater SNR enhancement for $0.06 \mathrm{mmol} / \mathrm{kg}$ vs. $0.03 \mathrm{mmol} / \mathrm{kg}$ for the LMS $(23.03 \pm 7.45$ vs. $12.37 \pm$ $3.91, \mathrm{p}<0.001), \mathrm{LAD}(26.12 \pm 9.86$ vs. $15.20 \pm 3.88, \mathrm{p}=$ $0.001)$, and RCA (29.54 \pm 11.64 vs. $18.13 \pm 6.29, \mathrm{p}=0.01)$. CNR comparisons revealed similar results. Qualitatively, similar number of main and branch vessels were identified by two reviewers (Figure 2).

\section{Conclusions}

Quantitatively, a double dose of Gadofosveset shows improvement in coronary arterial enhancement over clinical dose. Ongoing research is aimed at evaluating the diagnostic efficacy of a double-dose scanning regimen.

\section{Funding}

Funded by the National Institutes of Health (NIH) Intramural program.

\section{Authors' details}

${ }^{1}$ Department of Radiology and Imaging Sciences, National Institutes of Health, Bethesda, Maryland, USA. ${ }^{2}$ Molecular Biomedical Imaging Laboratory, National Institute of Biomedical Imaging and Bioengineering, Bethesda, Maryland, USA. ${ }^{3}$ Biomedical Imaging Research Institute, Cedars Sinai Medical Center, Los Angeles, California, USA. ${ }^{4}$ Centre for Advanced Cardiovascular Imaging, William Harvey Research Institute, Queen Mary, University of London, Barts and The London National Institute for Health Research Biomedical Research Unit, London, UK. ${ }^{5}$ Departments of Radiology and Biomedical Engineering, Northwestern University, Chicago, Illinois, USA.

Published: 16 January 2014

\section{References}

1. Pang J, Bhat $H$, Sharif B, et al: Whole-heart coronary MRA with $100 \%$ respiratory gating efficiency: Self-navigated three-dimensional retrospective imagebased motion correction (TRIM). Magn Reson Med, doi: $10.1002 / \mathrm{mrm} .24628$.

2. Scanlon PJ, Faxon DP, Audet AM, et al: ACC/AHA guidelines for coronary angiography: executive summary and recommendations. A report of the American College of Cardiology/American Heart Association Task Force on Practice Guidelines (Committee on Coronary Angiography) developed in collaboration with the Society 
for Cardiac Angiography and Interventions. Circulation 1999, 99:2345-2357.

doi:10.1186/1532-429X-16-S1-P158

Cite this article as: Raman et al:: Gadofosveset trisodium in coronary

magnetic resonance angiography at 3 Tesla. Journal of Cardiovascular Magnetic Resonance 2014 16(Suppl 1):P158.

Submit your next manuscript to BioMed Central and take full advantage of:

- Convenient online submission

- Thorough peer review

- No space constraints or color figure charges

- Immediate publication on acceptance

- Inclusion in PubMed, CAS, Scopus and Google Scholar

- Research which is freely available for redistribution

Submit your manuscript at www.biomedcentral.com/submit

() Biomed Central 